\title{
EDUCATIONAL ASSESSMENT FOR STUDENT LEARNING OF ORAL SKILLS THROUGH A DIGITAL RUBRIC
}

\author{
T. Linde-Valenzuela ${ }^{1}$, M.G. Veytia Buchely ${ }^{2}$ \\ 1 University of Málaga (SPAIN) \\ 2 Universidad Autónoma de Hidalgo (MEXICO) \\ teresalv@uma.es, maria_veytia@uaeh.edu.mx
}

\begin{abstract}
In the context of Higher Education, the students assessment is proving to be absolutely crucial to educational process (Sambell, McDowell \& Montgomery, 2013). When the students are involved actively in their assessment, the analysis capacity of them are configured, as well as their valuing learning. In addition to this, oral skills are very important and a basic capacity for the future teachers' job (Fernández et al., 2008; Okoli, 2017). This paper presents the oral skills assessment process (Bolívar et al., 2013) of two groups of teachers in initial training, the first one from the University of Malaga (Spain), and the second one from the Autonomous University of the State of Hidalgo (Mexico). The 360-degree evaluation is done through a digital rubric, which allows a collaborative, democratic and participatory evaluation. The results show the satisfaction level towards the technological tool used (Deeley, 2018), and the usability level of the rubric to assess the oral competences by the students themselves (Verano-Tacoronte et al., 2016).
\end{abstract}

Keywords: educational assessment, higher education, speech skills, preservice teacher education, educational innovation 